\title{
Effects of Line Spacing on Reading Performance of Normally Sighted and Simulated Visually-Impaired Subjects: A Pilot Study Using Arabic Words
}

\author{
Abdullah Z. Alotaibi ${ }^{1}$ \\ ${ }^{1}$ Department of Optometry and Rehabilitation Research Chair, College of Applied Medical Sciences, King Saud \\ University \\ Correspondence: Dr Abdullah Z. Alotaibi, Department of Optometry and Rehabilitation Research Chair, College \\ of Applied Medical Sciences, King Saud University, P O Box- 10219 Riyadh 11433, Saudi Arabia. Tel: \\ 96-614-355-010 Ext. 556.
}

Received: April 2, 2017 Accepted: April 28, 2017 Online Published: May 29, 2017

doi:10.5539/gjhs.v9n8p84 URL: https://doi.org/10.5539/gjhs.v9n8p84

\begin{abstract}
The study aims to evaluate the role of line spacing during reading in normal and visually-impaired persons. A total of 225 normally-sighted participants with mean age of 23.7 years were asked to read Arabic sentences in a randomized order. Each Arabic sentence contains 7 lines with and without simulated cataract. The words were printed with black letters on white background to enhance contrast and fonts were in Times New Roman and of N12 letter size. The reading pages were placed on reading stand situated $25 \mathrm{~cm}$ away from the subject's eyes. The simulated cataract was created by using a Bernell Cling Patch Occluder. This reduced the visual acuity of all subjects to 20/60. Each line of the text was separated by different line spacing namely: single space, 1.5, 2.0, 2.5, 3.0 and 4.0 which represents, $0.5 \mathrm{~cm}, 0.8 \mathrm{~cm}, 1.1 \mathrm{~cm}, 1.4 \mathrm{~cm}, 1.7 \mathrm{~cm}$ and $2.0 \mathrm{~cm}$, respectively. The sheets were presented randomly and participants' voices were recorded as they read under a controlled time. The tape was analysed later and reading rate was calculated. There was a significant difference $(p<0.0001)$ in reading rates between the normal sighted persons and the visually impaired persons for all line spacing. Modifying the spacing between lines in prints had a significant impact $(\mathrm{p}<0.0001)$ on the reading rate of the visually impaired but not in normally-sighted persons $(p>0.05)$. Intermediate line spacing ( 2 and 2.5$)$ increased the reading rate of the visually impaired persons significantly more $(p<0.001)$ than other line spacing, but smaller or larger line spacing slowed their reading rate, significantly $(\mathrm{p}<0.001)$. The visually-impaired persons reported that they felt the difference in reading prints with larger line spacing as compared with normal sighted participants who did not. It is beneficial to adequately modify the line spacing in prints commonly read by low vision persons. For Arab subjects the optimum line spacing to significantly improve reading in the visually impaired should range from 0.8 to $1.1 \mathrm{~cm}$. This finding may be a useful for publishers of Arab prints targeting the visually impaired persons. Thus, the implication of the study in the field of health is that by establishing the least common line spacing visualized optimally among normal and simulated visually impaired persons would be fixed as default line spacing for Arab printing to achieve better reading performance.
\end{abstract}

Keywords: reading, low vision, line spacing, visual impairment, cataract

\section{Introduction}

Reading is an active process required to gain more knowledge, practice as well as improving learning skills (Blackmore-Wright, Georgeson, \& Anderson, 2013). Previous research reports suggested that during reading, many complicated mental process were activated to interpretate the perceptions and connotations which inspired through recognition of printed symbols (Alotaibi, 2007; Rayner, Pollatsek, Ashby, \& Clifton Jr, 2012; Resnick \& Weaver, 2013; Walker, 1988).

Successful reading may differs among individuals; it depends mainly on the ability of each individual to extract information from printed materials with an adequate speed. Many older people have difficulty reading standard text, including medical information, hospital forms, and medication labels. Some people who can read standard print may find it tiring and prefer to read large print whenever they can (Alotaibi, 2007).

In clinical low vision practice, reading is probably the most communal functional problem reported by patients 
(Alotaibi, 2007). For the many individuals with vision loss, reading presents a major challenge(Baldasare, Watson, Whittaker, \& Miller-Shaffer, 1986; Wolffsohn \& Cochrane, 2000). In terms of reading, low vision can be defined as the inability to read the newspaper or recognize faces, even using corrective lenses, at a normal reading distance of $40 \mathrm{~cm}$ (Legge, Mansfield, \& Chung, 2001).

Consequently, many attempts were made to study the effect of using low vision aids to improve the reading performance of partially sighted subjects. Studies have shown that reading rate is significantly reduced when magnifiers are used (Binns et al., 2009; Cheong, Lovie - Kitchin, \& Bowers, 2002; Cohen \& Waiss, 1991; Dickinson \& Shim, 2007; Mancil \& Nowakowski, 1986; Neve, 1989). This is due to restriction to the horizontal field of view and difficulty in manipulating the magnifiers during reading as compared with reading rate on large print (Bowers, 2000).

Reading problems existed among visually impaired individuals activates more research investigators since long time to find a solution but up till now it was not very fruitful. Most textual manipulations, have led to only modest gains in reading speed (Aries Arditi, 2004), and the most common typographical features that have been modified by researchers is the print size(Bouma, Legein, Melotte, \& Zabel, 1982; Cakmak, Karakoc, Safak, \& Kan, 2014; Legge, Rubin, Pelli, \& Schleske, 1985; Lueck et al., 2003; Virgili, Acosta, Grover, Bentley, \& Giacomelli, 2013).

Few studies have also modified the font size, letter case, test spacing and assessed its effect on reading performance of normally-sighted subjects and subjects with low vision (Alotaibi, 2007; Aries Arditi \& Cho, 2007; Susana TL Chung, 2012; Mansfield, Legge, \& Bane, 1996; Russell-Minda, Jutai, Strong, \& Campbell, 2007).

Consequently, there is still no clear consensus on the optimal text parameters for reading in the visually-impaired persons. He, Legge, and $\mathrm{Yu}$ (2013) studied the spatial integrative properties of peripheral retina. They suggested that 'visual crowding' may be a major factor contributing to inefficient reading. Crowding refers to the fact that a target (e.g. letter or word) in the peripheral visual field is much harder to identify in the presence of nearby targets (Pelli, Palomares, \& Majaj, 2004; Pelli et al., 2007).

Line spacing is another important typographical feature that received a little or no attention compared to increasing the print size which is the most straight forward method reported to improve reader's performance. Line spacing may play significant role in improving reading rate of normally-sighted subjects and low vision patients. Studies (Paterson \& Tinker, 1947; Soleimani \& Mohammadi, 2012; Tarita-Nistor, Lam, Brent, Steinbach, \& González, 2013; Thomas, Barker, Rubin, \& Dahlmann-Noor, 2015) measured the reading speed of normally-sighted subjects when they read materials of different font sizes. They found that, all materials with different line spacing were read faster than text set solid. Whereas, text with $4(0.14 \mathrm{~cm})$ and $5(0.17 \mathrm{~cm})$ space between lines produced the fastest reading speed (Paterson \& Tinker, 1947).

English and Arabic language are two very contrasting languages with different morphological structures (Alotaibi, 2007). Previous studies were performed using English language to evaluate the effects of different typographical features on reading. However, only one study was reported to assess the effects of modified acuity reserve and font (but not line spacing) on reading by using Arabic language (Alotaibi, 2007). No study has explored the influence of line spacing on readers of Arabic language.

English has a concatenative morphological structure (morphemes follow one another linearly) while Arabic has a non-concatenative structure that is based on the notion of root. In Arabic language, vocabulary is built in root and generally composed of three consonants (Alotaibi, 2007; Ibrahim, Khateb, \& Taha, 2013; Taha, 2013). The aim of this study was to investigate the effect of different line spacing on the reading performance of normally sighted subjects and simulated visually-impaired subjects.

\section{Methods}

\subsection{Participants}

Two hundred and twenty five, normally sighted participants (150 males and 75 females), who were undergraduate students at King Saud University, participated in this study. The average age of the subjects was 23.7 years and all participants were native Arabic speakers. Written informed consent was obtained from all participating subjects after explanation of the study requirements. Study protocol adhered to the Declaration of Helsinki and was approved by the Research Ethics Committee of King Saud University.

\subsection{Materials}

All subjects read pages with Arabic sentences each containing 7 lines as previously mentioned (Alotaibi, 2007). To increase the contrast of reading pages, the words were printed with black letters on white background of A4 sheets. The reading pages were placed on reading stand situated $25 \mathrm{~cm}$ from the subject's eyes. Times New Roman font 
was used because as the print size increased, Time New Roman (TNR) was read faster (A. Arditi, Knoblauch, \& Grunwald, 1990; S. T. Chung, 2004). The authors measured reading speeds with proportionally spaced (TNR) and fixed-width (Courier) versions. For large print size, proportionally spaced text was read faster than fixed-width text, whereas with small print, proportionally spaced text was read considerably slower than fixed-width text. Also, Times New Roman is a proportionally-spaced font similar to that used in Arabic daily newspaper. Books and magazines are couriers that have fixed-width similar to that produced by typewriters or some computer displays (Alotaibi, 2007).

Simulated visual impairment was used to represent cataract. It is important as a first step in the validation of a measurement tool, to determine the inherent reliability using a homogeneous sample of subjects who are unlikely to introduce any additional confounding factors that could affect the measurement of interest, in this case reading performance (e.g. the fluctuation of vision, change in the reading behaviour). For this reason, people with normal vision rather than low vision were selected as the subjects for this validation study. Also, subjects suffering from a real cataract may vary in different aspects such as the shape and location of the cataract, visual acuity, age and additional pathologies which are difficult to standardize along with different print sizes. The simulated cataract was created by using a Bernell Cling Patch Occluder which was made from a static-cling material that was reusable (Alotaibi, 2007). This occluder reduced the visual acuity of all subjects to 20/60. Subsequently, the acuity reserve of the subjects was measured using the following method: when the visual acuity of the subject was determined $(6 / x)$, the near acuity was calculated as $(x / 3)$, which determined the print size at which the subject read at his/her threshold (Bouma, Legein, Melotte, \& Zabel, 1982).

The size of the letters used in this study was N12, so that the acuity reserve was at least $6: 1$ for normally sighted and it was 2:1 for simulated cataract subjects. This size of

print was used, because an improvement in reading performance has been noticed when the text print was above an acuity threshold of readers(Whittaker \& Lovie-Kitchin, 1993). The text consists of 7 lines and each line was separated by different line spacing (single space, 1.5, 2.0, 2.5, 3.0 and 4.0). Single space was equal to $0.5 \mathrm{~cm}, 1.5$ space was $0.8 \mathrm{~cm}, 2.0$ space was $1.1 \mathrm{~cm}, 2.5$ space was $1.4 \mathrm{~cm}, 3.0$ space was $1.7 \mathrm{~cm}$ and 4.0 space was $2.0 \mathrm{~cm}$, measured as the distance between the lower part of the upper letter and the upper part of lower letters adjacent lines.

\subsection{Data Collection}

Participants were asked to read binocularly the words aloud, as if they were reading a newspaper or a magazine. First data were collected without simulated cataract and then with simulated cataract. The sheets were presented randomly and subjects were recommended to report any intention to halt if they felt tired. Participants' voices were recorded using a portable cassette recorder and a microphone which was placed at the right side of reading stand. The time was controlled using a digital watch with a precision of one second. The tape was analysed later and reading rate was calculated as the number of words read correctly divided by the time taken to read the task as mentioned previously (Alotaibi, 2007).

\subsection{Statistical Analysis}

Analysis was done using SPSS Statistics for Windows version 21.0 (IBM Corp., Armonk, NY, USA). P values < 0.05 were considered statistically significant. The Shapiro-Wilk test confirmed the normality of distribution of the data sets across the different line spacing for normally-sighted and simulated visually impaired subjects: thus data analysis was performed using parametric tests. Data were expressed as mean reading rate. Repeated measures ANOVA assessed the differences in reading rate across different line spacing with a within subject factor (line spacing) and a between subject factor (condition: normally-sighted and simulated visually impaired subjects).

\section{Result}

Figure 1 is a combined graph of reading rate as a function of line spacing for the normally sighted (thick lines) and visually impaired simulated subjects (dotted lines). As expected, the former read significantly faster $(\mathrm{p}<0.0001)$ than the later regardless of the line spacing of the prints and in both cases, the reading rate was slightly better with the 2.5 line spaced prints than with other line spacing. In other word, normally sighted subjects were read fasterin term of reading rate- than visually impaired simulated subjects. However, both read faster as line spacing increased to 2.5. This result indicates that, the reading rate was slow when smaller and larger than 2.5 line spacing was used.

\subsection{Normally Sighted Subjects}

There were little variations in the reading rate when different line spacing were used, which were not statistically 
significant $(\mathrm{p}=0.1)$. Figure 1 shows that the reading rate of the normally sighted subjects increased steadily as the spaces between lines increased and peaked when the spaces between lines was 2.5. The slope from one line spacing to 2.5 line spacing was 0.031 . Beyond this point, there was a reduction in reading rate of -0.032 per line spacing. Most of the subjects reported they did not notice any effect of line spacing on their reading performance.

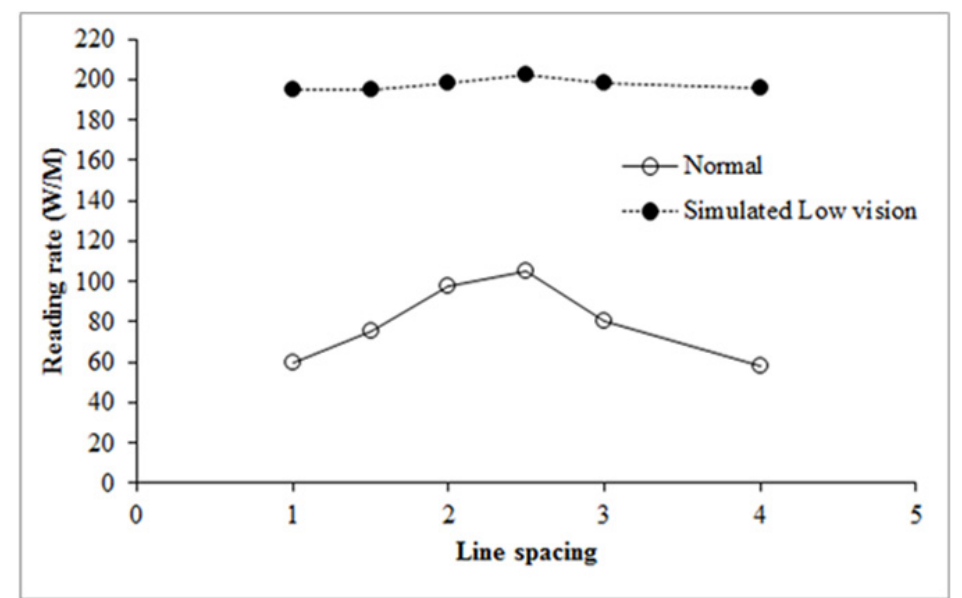

Figure 1. Reading rate as a function of line spacing in normally-sighted and simulated low vision subjects

\subsection{Visually Impaired Simulated Subjects}

Line spacing had significant effects on the reading rate of the visually impaired simulated subjects $(p=0.0001)$. Figure 2 shows a similar pattern of change in reading rate as line spacing was increased in cataract-simulated subjects when compared with optimum line space (2.5). There was a significant increase in reading rate (rate of increase was $0.182 \mathrm{w}$ per line spacing) when the spacing between lines was increased from one to 2.5 , and a more drastic decline in reading rate $(-0.232$ per line spacing $)$ when the spacing between lines was larger than 2.5. In other words, the reading rate was slow when smaller and larger than 2.5 line spacing was used. Therefore, further analysis was conducted to assess the relative reading rate with the 2.5 line spacing as a reference.

This was calculated as difference in line space/intermediate line space (2.5) and the result was plotted as a function of different line spaces for simulated visual impairment. When values were smaller than one value, it indicates that the intermediate line spaced (2.5) prints were read faster than other line spaces and vice versa for values greater than one. The results shown in Figure 2 indicate that all values were less than one. Most of the subjects reported that, they read better when the line spacing was increased.

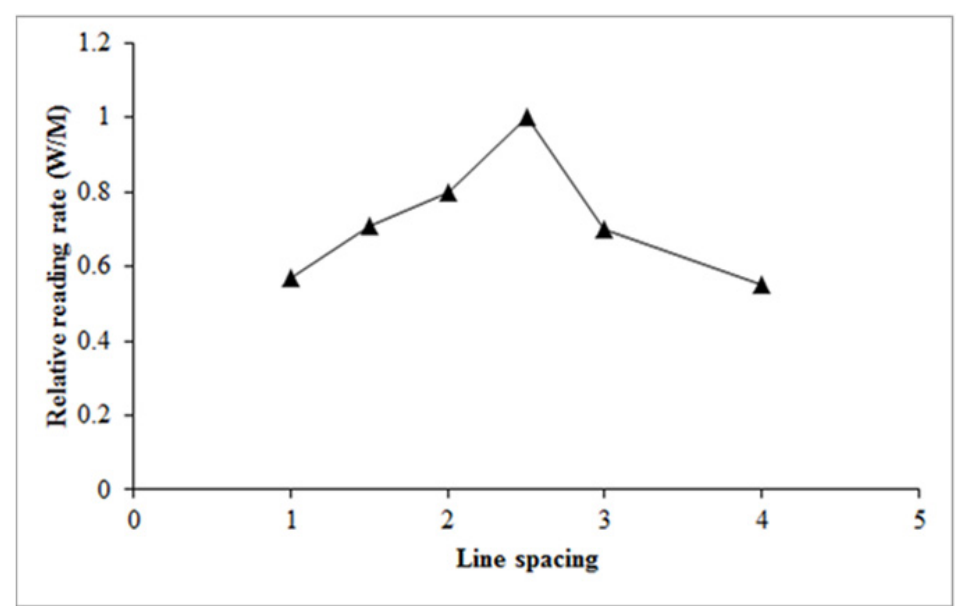

Figure 2. Relative reading rate as a function of line spacing in simulated low vision subjects. When values were smaller than one, it indicates that the intermediate line spaced (2.5) prints were read faster than other line spaces and vice versa for values greater than one 


\section{Discussion}

Successful reading hinge totally on the capability of readers to extract information from printed symbols at a satisfactory speed. The typographical features of the text are likely to be very important in reading especially for partially sighted patients (Alotaibi, 2007).

In this study, we investigated the effect of line spacing, on reading Arabic text by normally and simulated visually impaired subjects. The result shows that, there are significant improvements in the reading rate of the simulated visually impaired subjects when prints with intermediate line spaces ( 2 and 2.5) were read (Figures 1 and 2) but not for the normally-sighted subjects (Figure 1).

The Visually impaired simulated subjects read very slowly when asked to read prints with line spacing smaller than 2. This could be attributed to the fact that, as the visual acuity of the subjects was reduced (acuity reserve 2:1), it became difficult for the subjects - particularly in case of the single spaced lines - to accurately find the beginning of the next line. They missed a line or reread a line previously read, and sometimes they read the next line in the middle of the current line, thereby reducing their reading rate. The other reason we observed was that, the simulated visually impaired participants had difficulties finding the next line as they read compared with normally-sighted participants.

This contributed to the significant decrease in reading rate of simulated cataract participants. When the spaces between the lines was increased (intermediate line spaces used), this problem disappeared such that the lines were close enough to guide the eyes back to the beginning of the next line, but , they were not so close as to confuse the subjects. This result is consistent with previous findings (S. T. Chung, 2004; Russell-Minda et al., 2007). Increase the line spaces to three or four spaces had a negative influence on the reading rate of the visually impaired persons but not on the normal persons as shown in Fig. 1.

At wider line spacing, the reading rate dropped and became similar with that found for single line spacing. This may have occurred because the visually-impaired person needs more time to return to the next line.

Wider spaces between lines translate to an increase in the distance which the participants' eyes have to make in order to move back to the next line. This involves several saccades, which the visually impaired person is unfamiliar with and may have affected their page navigation. Thus, the significant slower reading rate observed in the simulated visually impaired persons compared with normal sighted persons. Blackmore-wright and colleagues found that double and triple line spacing yielded significantly greater reading speed than single line spacing. Participants were tested with low and high contrast test cards (Blackmore-Wright et al., 2013).

The result of the study is important to low vision persons of Arab origin particularly those unable to understand English language. It indicates that adequate modification of line spacing of prints commonly read by low vision persons (especially using intermediate line spacing) would improve their reading performance and enhance their daily activities.

These findings may be used as a guide for publishers in determining the optimum line space of printed materials which will lead to a faster reading rate for low vision patients.

The implication of the study is that by establishing the least common line spacing visualized optimally among normal and visually impaired simulated subjects would be fixed as default line spacing for Arab printing to achieve better reading performance. Thus, this acquired default line spacing can be generalized for both normal as well as visually impaired in Arabian countries. Overall, it could be cost effective especially where both normally and simulated visually impaired person work together.

\section{Acknowledgements}

The author is grateful to the Deanship of Scientific Research, King Saud University for funding through Vice Deanship of Scientific Research Chairs.

\section{Competing Interests Statement}

The author declares that there is no competing or potential conflict of interest regarding the publication of this paper.

\section{References}

Alotaibi, A. Z. (2007). The effect of font size and type on reading performance with Arabic words in normally sighted and simulated cataract subjects. Clin Exp Optom, 90(3), 203-206. https://doi.org/10.1111/j.1444-0938.2007.00123.x

Arditi, A. (2004). Adjustable typography: an approach to enhancing low vision text accessibility. Ergonomics, 
47(5), 469-482. https://doi.org/10.1080/0014013031000085680

Arditi, A., \& Cho, J. (2007). Letter case and text legibility in normal and low vision. Vision Research, 47(19), 2499-2505. https://doi.org/10.1016/j.visres.2007.06.010

Arditi, A., Knoblauch, K., \& Grunwald, I. (1990). Reading with fixed and variable character pitch. J Opt Soc Am A, 7(10), 2011-2015. https://doi.org/10.1364/JOSAA.7.002011

Baldasare, J., Watson, G. R., Whittaker, S. G., \& Miller-Shaffer, H. (1986). The development and evaluation of a reading test for low vision individuals with macular loss. Journal of Visual Impairment \& Blindness.

Binns, A., Bunce, C., Dickinson, C., Harper, R., Tudor-Edwards, R., Woodhouse, M., . . Lindsay, J. (2009). Low vision service outcomes: a systematic review. Low visions service model evaluation project. London: RNIB.

Blackmore-Wright, S., Georgeson, M. A., \& Anderson, S. J. (2013). Enhanced text spacing improves reading performance in individuals with macular disease. PloS one, 8(11), e80325. https://doi.org/10.1371/journal.pone.0080325

Bouma, H., Legein, C., Melotte, H., \& Zabel, L. (1982). Is large print easy to read?: oral reading rate and word recognition of elderly subjects. IPO Annual Progress Report, 17, 84.

Bowers, A. R. (2000). Eye movements and reading with plus-lens magnifiers. Optometry \& Vision Science, 77(1), 25-33. https://doi.org/10.1097/00006324-200001000-00010

Cakmak, S., Karakoc, T., Safak, P., \& Kan, A. (2014). Identifying the reading speed of low vision student's at elementary level. International Journal in IT \& Engineering, 2(10), 38-48.

Cheong, A. M., Lovie - Kitchin, J. E., \& Bowers, A. R. (2002). Determining magnification for reading with low $\begin{array}{llll}\text { vision. Clinical and } & \text { Experimental 229-237. }\end{array}$ https://doi.org/10.1111/j.1444-0938.2002.tb03042.x

Chung, S. T. (2004). Reading speed benefits from increased vertical word spacing in normal peripheral vision. Optom Vis Sci, 81(7), 525-535. https://doi.org/10.1097/00006324-200407000-00014

Chung, S. T. (2012). Dependence of reading speed on letter spacing in central vision loss. Optometry and vision science: official publication of the American Academy of Optometry, 89(9), 1288. https://doi.org/10.1097/OPX.0b013e318264c9dd

Cohen, J. M., \& Waiss, B. (1991). Reading speed through different equivalent power low vision devices with $\begin{array}{lllll}\text { identical field of view. Optometry \& Vision Science, 68(10), } & \text { 795-797. }\end{array}$ https://doi.org/10.1097/00006324-199110000-00007

Dickinson, C., \& Shim, M. (2007). The influence of manual dexterity on reading speed with a hand-held magnifier. Investigative Ophthalmology \& Visual Science, 48(9), 4368-4374. https://doi.org/10.1167/iovs.07-0001

He, Y., Legge, G. E., \& Yu, D. (2013). Sensory and cognitive influences on the training-related improvement of reading speed in peripheral vision. Journal of Vision, 13(7), 14-14. https://doi.org/10.1167/13.7.14

Ibrahim, R., Khateb, A., \& Taha, H. (2013). How Does Type of Orthography Affect Reading in Arabic and Hebrew as First and Second Languages? Open Journal of Modern Linguistics, 3(01), 40. https://doi.org/10.4236/ojml.2013.31005

Legge, G. E., Mansfield, J. S., \& Chung, S. T. (2001). Psychophysics of reading: XX. Linking letter recognition to reading speed in central and peripheral vision. Vision Research, 41(6), 725-743. https://doi.org/10.1016/s0042-6989(00)00295-9

Legge, G. E., Rubin, G. S., Pelli, D. G., \& Schleske, M. M. (1985). Psychophysics of reading-II. Low vision. Vision Research, 25(2), 253-265. https://doi.org/10.1016/0042-6989(85)90118-X

Lueck, A. H., Bailey, I. L., Greer, R. B., Tuan, K. M., Bailey, V. M., \& Dornbusch, H. G. (2003). Exploring print-size requirements and reading for students with low vision. Journal of Visual Impairment and Blindness, 97(6), 335-354.

Mancil, G. L., \& Nowakowski, R. (1986). Evaluation of reading speed with four low vision aids. Optometry \& Vision Science, 63(9), 708-713. https://doi.org/10.1097/00006324-198609000-00003

Mansfield, J. S., Legge, G. E., \& Bane, M. C. (1996). Psychophysics of reading. XV: Font effects in normal and low vision. Investigative Ophthalmology \& Visual Science, 37(8), 1492-1501. 
Neve, J. J. (1989). Reading with hand-held magnifiers. Journal of medical engineering \& technology, 13(1-2), 68-75. https://doi.org/10.3109/03091908909030198

Paterson, D. G., \& Tinker, M. A. (1947). Influence of leading upon readability of newspaper type. Journal of Applied Psychology, 31(2), 160. https://doi.org/10.1037/h0054188

Pelli, D. G., Palomares, M., \& Majaj, N. J. (2004). Crowding is unlike ordinary masking: Distinguishing feature integration from detection. Journal of Vision, 4(12), 12-12. https://doi.org/10.1167/4.12.12

Pelli, D. G., Tillman, K. A., Freeman, J., Su, M., Berger, T. D., \& Majaj, N. J. (2007). Crowding and eccentricity determine reading rate. Journal of Vision, 7(2), 20-20. https://doi.org/10.1167/7.2.20

Russell-Minda, E., Jutai, J. W., Strong, J. G., \& Campbell, K. A. (2007). The legibility of typefaces for readers with low vision: A research review. Journal of Visual Impairment \& Blindness, 101(7), 402.

Soleimani, H., \& Mohammadi, E. (2012). The effect of text typographical features on legibility, comprehension, and retrieval of EFL learners. English Language Teaching, 5(8), 207. https://doi.org/10.5539/elt.v5n8p207

Taha, H. Y. (2013). Reading and spelling in Arabic: Linguistic and orthographic complexity. Theory and Practice in Language Studies, 3(5), 721. https://doi.org/10.4304/tpls.3.5.721-727

Tarita-Nistor, L., Lam, D., Brent, M. H., Steinbach, M. J., \& González, E. G. (2013). Courier: a better font for reading with age-related macular degeneration. Canadian Journal of Ophthalmology/Journal Canadien d'Ophtalmologie, 48(1), 56-62. https://doi.org/10.1016/j.jcjo.2012.09.017

Thomas, R., Barker, L., Rubin, G., \& Dahlmann-Noor, A. (2015). Assistive technology for children and young people with low vision. Cochrane Database of Systematic Reviews, (6). https://doi.org/10.1002/14651858.CD011350.pub2

Virgili, G., Acosta, R., Grover, L., Bentley, S., \& Giacomelli, G. (2013). Magnifying reading devices or aids for adults with low vision. Health.

Whittaker, S. C., \& Lovie-Kitchin, J. (1993). Visual requirements for reading. Optom Vis Sci, 70, 54-65. https://doi.org/10.1097/00006324-199301000-00010

Wolffsohn, J. S., \& Cochrane, A. L. (2000). Design of the low vision quality-of-life questionnaire (LVQOL) and measuring the outcome of low-vision rehabilitation. American journal of ophthalmology, 130(6), 793-802. https://doi.org/10.1016/S0002-9394(00)00610-3

\section{Copyrights}

Copyright for this article is retained by the author(s), with first publication rights granted to the journal.

This is an open-access article distributed under the terms and conditions of the Creative Commons Attribution license (http://creativecommons.org/licenses/by/4.0/). 